\title{
EXCISION OF BRACHIAL ARTERY PSEUDOANEURYSM IN A NON-ISCHEMIC BUT PARALYSED LIMB WITH UNFAVOURABLE ANATOMY: ROLE OF DIGITAL PULSE OXIMETRY AND CT ANGIOGRAPHY IN DECIDING TO RECONSTRUCT OR NOT?
}

\author{
Ashish Sharma1, Palash Aiyer2, Vijay Grover ${ }^{3}$, Vijay Gupta ${ }^{4}$ \\ ${ }_{1}^{1}{ }^{\text {rd }}$ Year Senior Resident, Department of Cardiothoracic and Vascular Surgery, Dr. Ram Manohar Lohia Hospital, New Delhi. \\ ${ }^{2}$ Assistant Professor, Department of Cardiothoracic and Vascular Surgery, Dr. Ram Manohar Lohia Hospital, New Delhi. \\ ${ }^{3}$ Professor, Department of Cardiothoracic and Vascular Surgery, Dr. Ram Manohar Lohia Hospital, New Delhi. \\ 4 Professor and HOD, Department of Cardiothoracic and Vascular Surgery, Dr. Ram Manohar Lohia Hospital, New Delhi.
}

\section{ABSTRACT}

\section{BACKGROUND}

Pseudoaneurysms arise from contained arterial rupture resulting in a periarterial haematoma communicating with the arterial lumen. Natural history of pseudoaneurysms is marked by complications like cutaneous erosion, haemorrhage, venous oedema and compressive neuropathy. We describe a patient with long-standing pseudoaneurysm of brachial artery and severe neurological deficit in the upper limb resulting in a non-functional but viable limb. Treatment was also influenced by coexisting large matted axillary lymph nodes secondary to previous disseminated tuberculosis.

\section{KEYWORDS}

Brachial Artery, Pseuodoaneurysm, Pulse Oximetry.

HOW TO CITE THIS ARTICLE: Sharma A, Aiyer P, Grover V, et al. Excision of brachial artery pseudoaneurysm in a non-ischemic but paralysed limb with unfavourable anatomy: role of digital pulse oximetry and CT angiography in deciding to reconstruct or not? J. Evolution Med. Dent. Sci. 2016;5(42):2641-2642, DOI: 10.14260/jemds/2016/617

\section{INTRODUCTION}

A 25 years old female presented with a warm and tender swelling measuring $7.5 \times 5 \mathrm{~cm}$ in the medial aspect of right upper arm, which had been increasing in size for the past 6 months. The patient held her arm abducted at the right shoulder and had a 60-degree fixed flexion deformity at the elbow joint. Muscular atrophy along with wrist drop and complete anaesthesia of the right upper limb was present. Though there was no clinical evidence of ischemia, the pulsations of right brachial, radial and ulnar arteries were not palpable. Multiple enlarged and matted firm axillary lymph nodes were noted separately from the swelling. She had been treated 1 year ago with standard multidrug chemotherapy for disseminated pulmonary tuberculosis. She gave no history of limb trauma or arterial catheterization.

Arterial Doppler revealed a thrombosed pseudoaneurysm arising from right upper brachial artery with monophasic flow in distal brachial, radial and ulnar arteries. Normal triphasic flow was present in the right subclavian and axillary arteries. CT angiography (Figure 1) confirmed Doppler findings and showed presence of collateral circulation.

Surgical exploration revealed a large pseudoaneurysm arising from the proximal third of brachial artery extending into intermuscular plane between biceps, triceps and brachialis muscles with near complete destruction of adjacent arterial wall. Dense fibrotic encasement of median, radial and musculocutaneous nerves was noted (Figure 3). Pseudoaneurysm excision and neurolysis were performed.

Financial or Other, Competing Interest: None.

Submission 22-03-2016, Peer Review 20-04-2016,

Acceptance 29-04-2016, Published 26-05-2016.

Corresponding Author:

Dr. Ashish Sharma,

A 10 G1 Dilshad Garden,

New Delhi.

E-mail: drashish.sharma69@gmail.com

DOI: $10.14260 /$ jemds/2016/617
The decision "To revascularize or not" was a major issue as the limb was non-functional though viable. The presence of large matted lymph nodes encasing the axillary vessels posed a further challenge to vascular reconstruction. In view of normal capillary refill in the nail beds coupled with $100 \%$ oxygen saturation on digital pulse oximetry following occlusion of the brachial artery, we decided against graft reconstruction of the brachial artery. There was no clinical evidence of ischemia postoperatively. At 6 month follow-up, the limb remained viable but neurological recovery was poor. Histopathology revealed perivascular and transmural mixed lympho-histiocytic infiltrate in the brachial artery with luminal fibrin thrombus.

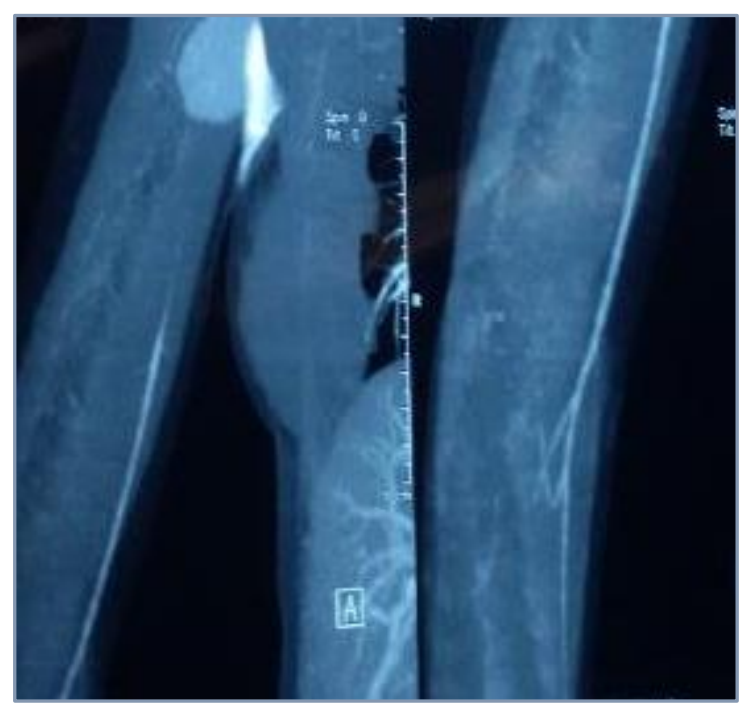

Fig. 1: CT Angio Film Showing Pseudoaneurysm Arising from Proximal Part of Right Brachial Artery with Poor Calibre Run off of Brachial Artery Distal to Lesion. The Ulnar and Radial Arteries Showed Normal Contrast Opacification through Collaterals 


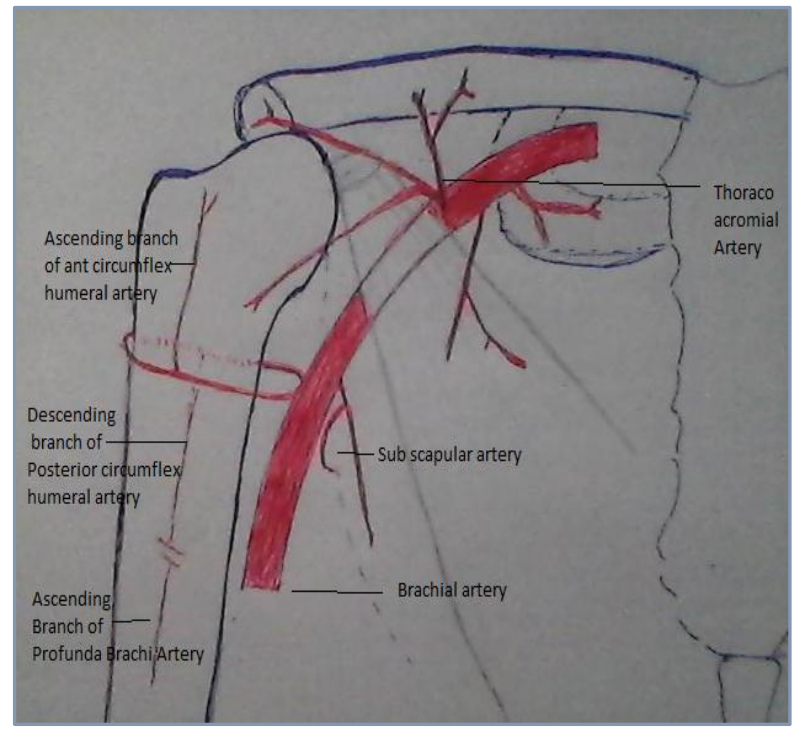

Fig. 2: Collateral Circulation in Upper Limb Following Ligation of the Upper Third of Brachial Artery is carried on by Branches from the Humeral Circumflex and Subscapular Arteries Anastomosing with Ascending Branches from the Profunda Brachii

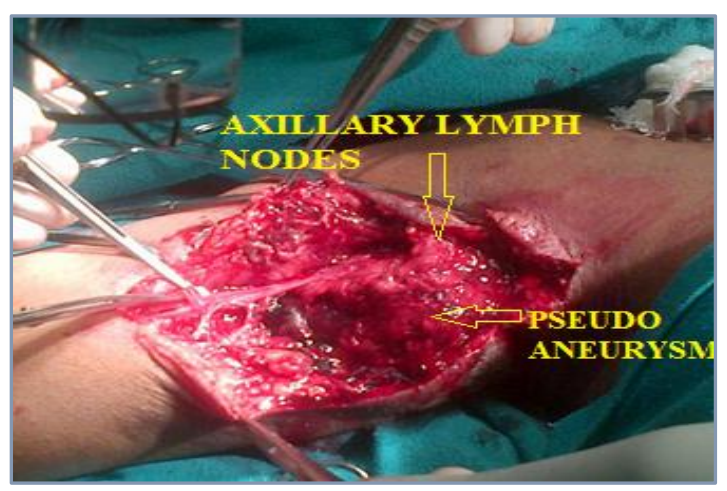

Fig. 3(A)

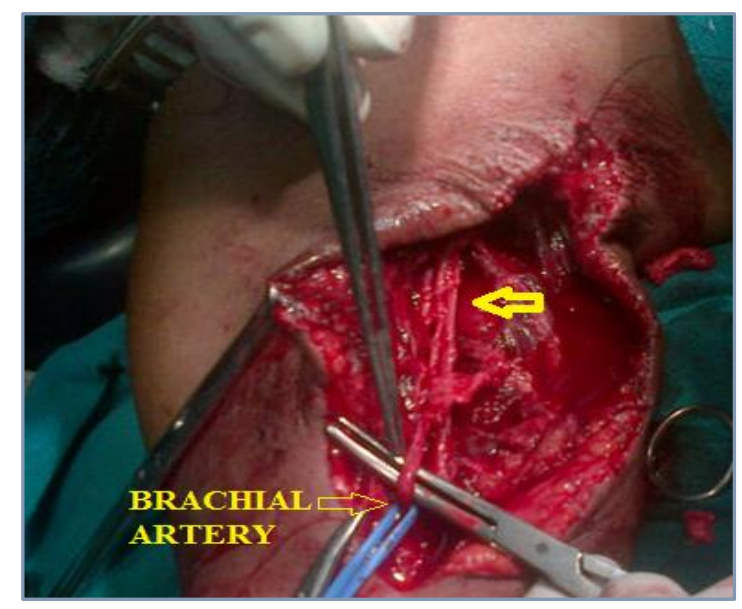

Fig. 3(B)

Intraoperative Picture: Fig. 3(A): Proximal Control at Right Subclavian Artery Level and Matted Right Axillary Lymph Nodes with Brachial Artery Pseudoaneurysm 3(B) Dense Fibrotic Encasement of Median, Radial and Musculocutaneous Nerves

\section{DISCUSSION}

Pseudoaneurysms are uncommon in the upper limb and are generally due to major trauma, syphilis, Marfan syndrome, infections. Various treatment modalities available to treat pseudoaneurysms are ultrasonographic manual compression, ligation of pseudoaneurysm, endovascular graft implantation, embolization, ultrasound-guided thrombin injection and surgical reconstruction. $(1,2,3,4,5)$ Surgical resection of pseudoaneurysm with arterial graft reconstruction is the procedure of choice for large pseudoaneurysms arising from major arteries. Special care must be taken with regard to brachial artery ligation, which can lead to amputation.(6,7) The amputation rate is more than $50 \%$ after brachial artery ligation versus $6 \%$ after reconstruction.(7) Presence of local infection or inflammatory pathology increases the chance of haemorrhage from disruption of the vascular repair.(7) In such a situation assessment of the distal collateral circulation is an important consideration. Resection of pseudoaneurysm with ligation of proximal and distal ends of the blood vessel can be done for the pseudoaneurysms arising from a chronically occluded vessel with a well-established distal collateral circulation. ${ }^{(8)}$ (Figure 2).

In our patient, vascular reconstruction of the brachial artery following pseudoaneurysm excision was deemed unnecessary and potentially harmful in a collateralised, nonfunctional limb in the presence of matted axillary lymph nodes.

In conclusion the clinical absence of limb ischemia and evidence of good capillary refill coupled with evidence of distal collateralisation on CT angiography helps in deciding if vascular reconstruction can be avoided where local anatomical or infectious pathology pose technical challenges. Monitoring of oxygen saturation and continuous waveform using digital pulse oximetry during proximal ligation of the brachial artery lends further evidence of a sufficiently collateralised limb and helps in decision making.

\section{REFERENCES}

1. Tetik 0 , Yetkin $U$, Yilik $L$, et al. Right axillary pseudoaneurysm causing permanent neurological damage at right upper limb: a case report. Turk J Vasc Surg 2002;2:102-4.

2. Nugud 00, Hedges AR. Axillary artery pseudoaneurysm. Int J Clin Pract 2001;55(7):494-9.

3. Napolitano AM, Napolitano L, Francomano F, et al. Aneurysms of the subclavian artery: clinical experience. Ann Ital Chir 1998;69(3):311-5.

4. Haimovici H. Peripheral arterial aneurysms. In: Haimovici $\mathrm{H}$, Ascer E, Hollier LH, editors. Haimovici's vascular surgery. Cambridge (MA): Blackwell Science; 1996;893909.

5. Cakir O, Balci AE, Eren S, et al. Traumatic arteriovenous fistulas. Turk J Vasc Surg 2001;1:28-31.

6. Rudolphi D. An update on the peripheral pseudoaneurysm. J Vasc Nurs 1993;11(3):67-70.

7. Rich NM, Baugh JH, Hughes CW. Significance of complications associated with vascular repairs performed in Vietnam. Arch Surg 1970;100(6):646-51.

8. Clark ET, Mass DP, Bassiouny HS, et al. True aneurysmal disease in the hand and upper extremity. Ann Vasc Surg 1991;5(3):276-81. 